\title{
ELISA STUDY OF OOCYST-SPOROZOITE TRANSITION IN MALARIA VECTORS
}

\author{
CZEHER C.*, LABBO R.*, DJIBRILlA A.", HERE L.*, ARZIKA I.* \& DUCHEMIN J.B.*
}

\section{Summary:}

Intrinsic vector characteristics and environmental factors affect the sporogonic development of $P$. falciparum in Anopheles mosquitoes. We tested for the presence of the circumsporozoite protein, as a marker of the oocyst to sporozoite transition in naturally infected Anopheles gambiae s.l. and Anopheles funestus. Malaria vectors were collected in a village in the Sahel of Niger during the rainy and dry seasons. ELISA-CSP was carried out on abdomen and head/thorax portions from more than 2,000 samples. No significant difference was found in the overall rates of infection of An. gambiae s.l. (4.13\%) and An. funestus $(3.58 \%)$. Given the differences in duration of the two parasite stages, P. falciparum CSP antigen prevalence was nearly as high in the abdomen as in the head/thorax, and did not differ significantly between An. gambiae s.l. and An. funestus. These preliminary results suggest that development from oocysts to salivary gland sporozoites is similar in the two vectors. However, these developmental indices varied as a function of the season in which samples were collected, particularly for An. gambiae s.l. This simple method may be useful for field studies assessing the effect of environmental and genetic factors on parasite survival.

KEY WORDS : Plasmodium falciparum, Anopheles gambiae, Anopheles funestus, ELISA, circumsporozoite protein, sporozoite, oocyst, Niger.
Résumé : ÉTUDE DE LA TRANSITION DES STADES OOCYSTE ET SPOROZOIITE CHEZ LES VECTEURS DU PALUDISME PAR LA MÉTHODE ELISA Le développement sporogonique de P. falciparum dans ses vecteurs est soumis aux conditions environnementales et est lié aux compétences génétiques des vecteurs. Nous avons étudié, à l'aide de la présence d'antigène circumsporozoiltaire, la prévalence des stades oocyste tardif et sporozoilte chez des vecteurs naturellement infectés. Des spécimens d'Anopheles gambiae s.l. et Anopheles funestus ont été collectés dans un village sahélien tout au long des saisons sèche et pluvieuse. La technique ELISA-CSP a permis de tester en parallèle les abdomens d'une part et, d'autre part, les têtes et thorax de plus de 2000 spécimens. Les taux d'infection globaux n'ont pas différé significativement entre An. gambiae s.l. $(4.13 \%)$ et An. funestus (3.58 \%). Aucune différence significative n'a été retrouvée dans les rapports entre prévalences sporozoïtaire et oocystique des deux vecteurs majeurs que sont An. gambiae s.l. (1.00) et An. funestus (0.85). Ces résultats préliminaires semblent indiquer une transition entre oocyste et sporozoïte comparable dans les populations vectrices testées. Cependant, ces indices varient de manière significative pour An. gambiae s.l. au cours des différentes périodes d'échantillonnage. Plusieurs facteurs potentiels de variation sont discutés. Ces premiers résultats montrent que cette méthode simple à mettre en oeuvre paraît prometteuse pour l'étude de la survie parasitaire en fonction de paramètres environnementaux ou vectoriels, qu'ils soient génétiques ou comportementaux.

MOTS CLÉS : Plasmodium falciparum, Anopheles gambiae, Anopheles funestus, ELISA, protéine circumsporozoïte, sporozoïte, oocyste, Niger.
$\mathrm{M}$ alaria parasites must undergo sporogonic development in the mosquito vector before infecting the mammalian host. Environmental factors place major constraints on the development of infectious parasites in the insect either directly, or indirectly, by influencing the abundance and lifespan of malaria vectors. Most environmental models of malaria are based largely on laboratory data. Most field studies make use of experimentally infected vectors and target the initial phases of parasite development, from gametocytes to young oocysts (Boudin \& Robert, 2003). The final phase of development, from older oocysts to sporozoites in the salivary glands, has been little stu-

\footnotetext{
* Centre de recherche médicale et sanitaire (CERMES), BP 10887 , Niamey, Niger.

Correspondence : Jean-Bernard Duchemin

Tel.: 227752040 - Fax: 227753180 - E-mail: duchemin@cermes.ne
}

died in field conditions. However, studies of parasite development within local vector populations in natural conditions are of prime importance for determining the overall significance of environmental constraints on "sporogonic" parasite populations.

If we assume that natural environmental conditions give rise to the small number of infected vectors, then very large numbers of samples must be tested, even in remote zones. The classical analysis method, involving the dissection of abdomens and salivary glands, is very time-consuming and requires fresh specimens. New techniques for estimating the frequencies of oocysts and sporozoites are therefore required. The circumsporozoite protein is a surface-associated product synthesized by sporozoites in older oocysts (Boudin et al., 1988). It is therefore present in the insect abdomen during sporozoite migration, and is transported to the salivary glands in this process. The late 
stages of sporogonic development can be studied by testing abdomen and head-thorax portions separately. As suggested by Beier et al. (1988), we used an enzyme-linked immunosorbent assay (ELISA) method that specifically detects Plasmodium falciparum circumsporozoite protein (CSP) (Burkot et al., 1984; Wirtz et al., 1987) in various portions of the mosquito. This marker can be used to assess the prevalence of oocysts and sporozoites in different vector populations.

Niger is a large country composed of three different bioclimatic areas with a large range of temperatures, and is home to three main malaria vectors (Julvez et al., 1998): Anopheles gambiae Giles 1902 sensu stricto (s.s.), Anopheles arabiensis Patton 1905, and Anopheles funestus Giles 1900. This makes it possible to study the influence of environmental factors, including climatic factors in particular, on parasite development in several vectors. In this preliminary study, we used the ELISA method to assess variations in CSP antigen prevalence in two body parts of the insect, as a function of transmission season, in vectors caught in one Nigerien village.

\section{MATERIALS AND METHODS}

T his study was conducted in Zindarou ( $13^{\circ} 26^{\prime} \mathrm{N}$, $2^{\circ} 55^{\prime} \mathrm{E}$ ), a village in the Nigerien Sahel region, classically defined as a meso-endemic malaria transmission zone with a rainy season between July and October and a rainfall peak during August and September. Mosquitoes were collected every two months from June 2004 to April 2005. Sampling methods included house-resting collections early in the morning and active landing-catch collections at night on adult people. We focused on the most prevalent local vectors: Anopheles gambiae sensu lato (s.1.) and Anopheles funestus. Mosquitoes were identified to species level on the basis of morphological criteria, using a local key. An. gambiae s.l. parity rates were estimated after dissecting the ovaries (Detinova, 1962) of a subset of samples for each sampling period. Specimens were then individually stored in 96-well microplates in dry conditions, at $-20^{\circ} \mathrm{C}$, in the laboratory.

We obtained head/thorax and abdomen specimens by cutting each individual mosquito between the anterior and median legs, and between the thorax and abdomen. We used ELISA to test for the presence of $P$. falciparum CSP in: 1) the head and third anterior portion of the thorax (salivary gland sporozoites); and 2) the abdomen portion (late-stage oocysts). ELISA-CSP was carried out as described by Burkot et al. (1984) and Wirtz et al. (1987). Two Culex sp. heads and two abdomens were used as negative controls and a $10 \mu \mathrm{g} / \mathrm{mL}$ CSP antigen solution was used as a positive control. Samples were considered positive if absorbance values exceeded twice the mean of the four negative controls (Beier et al., 1988). Sporozoite indices (i.e. salivary gland infection rates) were estimated for all specimens for which at least the head/thorax portion tested positive, whereas oocyst prevalences were estimated for all specimens in which at least the abdomen portion tested positive.

We studied a subset of An. gambiae s.l. specimens in the two main periods (rainy/dry), with An. gambiae s.s. and $A n$.arabiensis identified on the basis of direct PCR (Scott et al., 1993) on legs, without prior extraction of DNA.

We used Openepi 1.1 (www.openepi.com) for statistical analysis. Non-parametric methods ( $\mathrm{chi}^{2}$ test, contingency $\mathrm{chi}^{2}$ test) were used for non-normal data. The number of positive samples was low for both analyzed portions of the mosquitoes. We therefore clustered the sampling series into two periods: rainy season (August and October) and dry season (June then December, February and April) and carried out chisquared tests.

\section{RESULTS}

W e used ELISA to assess the levels of abdomen and head/thorax infection separately for 920 An. gambiae s.l. and 1,172 An. funestus collected over the study period (Table I). A total of 38 An. gambiae s.l. and 42 An. funestus tested positive for at least one of the two body parts, corresponding to $4.13 \%$ and $3.58 \%$ of the tested specimens. The difference between these two species was not significant for the study period as a whole $\left(\mathrm{chi}^{2}=0.42 ; \mathrm{df}=1\right.$; $\mathrm{p}=0.517)$. No significant difference was found between the two anatomic sites (Table I) of $P$. falciparum

\begin{tabular}{|c|c|c|c|c|}
\hline \multicolumn{2}{|c|}{ Infection localization } & \multicolumn{2}{|c|}{ Vector species } & \multirow[b]{2}{*}{ Total $(2,092)$} \\
\hline Abdomen & Head/Thorax & An. gambiae s.l. (920) & An. funestus $(1,172)$ & \\
\hline+ & - & $1.63 \%(15)[0.99-2.67]$ & $1.62 \%(19)[1.04-2.52]$ & $1.71 \%(34)[1.16-2.26]$ \\
\hline- & + & $1.63 \%(15)[0.99-2.67]$ & $1.28 \%(15)[0.78-2.1]$ & $1.44 \%(30)[1.01-2.04]$ \\
\hline+ & + & $0.87 \%(8) \quad[0.44-1.71]$ & $0.68 \%(8) \quad[0.35-1.34]$ & $0.80 \%(16)[0.47-1.24]$ \\
\hline \multicolumn{2}{|c|}{ Total } & $4.13 \%(38)[3.02-5.62]$ & $3.58 \%(42)[2.66-4.81]$ & $3.95 \%(80)[3.08-4.73]$ \\
\hline
\end{tabular}

Table I. $-P$. falciparum CSP antigen prevalences in malaria vectors for the whole study period. ( ) $=$ number of specimens tested (head of column) and positive (table). [ ] = $95 \%$ CI. 
infection in An. gambiae s.l. $\left(\mathrm{chi}^{2}=0.00 ; \mathrm{df}=1 ; \mathrm{p}=\right.$ 1.00) or in An. funestus ( $\mathrm{chi}^{2}=0.33$; df $=1 ; \mathrm{p}=0.567$ ). The calculated ratios of sporozoite rates to oocyst rates were $1.00(2.5 / 2.5)$ for An. gambiae s.l. and 0.85 (1.96/2.3) for An. funestus. Significant differences in total CSP prevalence, as a function of sampling time, were observed for An. gambiae s.l. (Contingency $\mathrm{Chi}^{2}=$ 17.10; $\mathrm{df}=5 ; \mathrm{p}=0.004$ ) whereas no such differences were observed for An. funestus (contingency $\mathrm{chi}^{2}=$ 4.64; $\mathrm{df}=4 ; \mathrm{p}=0.33$ ) (Fig. 1). The parity rate of Anopheles gambiae s.l. was not significantly different between the dry and rainy seasons, at $81 \%$ and $93 \%$, respectively $\left(\mathrm{chi}^{2}, \mathrm{p}=0.118\right)$. Molecular identification of members of the gambiae complex showed that the prevalence of $A n$. gambiae s.s. was $67 \%$ during the rainy season and $23 \%$ during the dry season ( $\mathrm{n}=53$, twotailed chi $^{2}$ test $\mathrm{p}=0.0018$ ). In the separate analyses for the two portions of the mosquitoes, we found that oocyst prevalence (abdomen) increased significantly ( $\mathrm{p}<0.0001)$ during the rainy season for An. gambiae s.l., whereas no such statistically significant change was observed for sporozoite prevalence (head/thorax) ( $\mathrm{p}=$ 0.059). For both species, the main variation in the overall frequency of mosquito infection paralleled that for oocyst prevalence (Fig. 1).
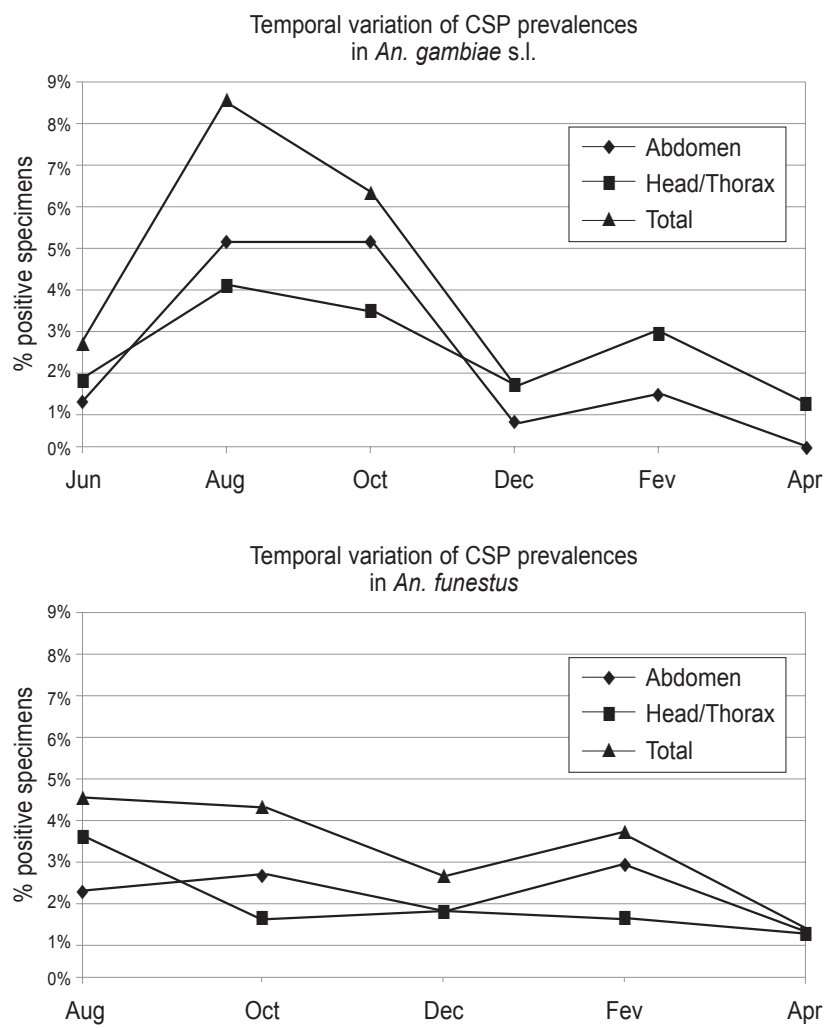

Fig. 1. - Temporal variation of the prevalence of CSP by ELISA method in different portions of samples of the two malaria vectors An. gambiae s.l. (top) and An. funestus (bottom). Squares: CSP in head and thorax, diamonds: CSP in abdomen, triangles: specimens positive either in abdomen or head/thorax.

\section{DISCUSSION}

O ur values for head/thorax CSP indices indicate that An. gambiae s.l. and An. funestus are highly efficient vectors in this Sahelian village. This high efficiency may be linked to the high survival rates of these populations despite extreme climatic conditions, as indicated by parity rates for An. gambiae s.l. These data provide the first information concerning the infection of vectors involved in P. falciparum transmission in Niger for more than twenty years. The last transverse study was carried out in December 1982 in a comparable zone (Baudon et al., 1983), and reported a prevalence of $0.7 \%$ for sporozoites in 1,416 dissected An. gambiae s.l. We obtained a higher prevalence for the same month and vector species (1.7\%), but the small number of specimens tested $(n=120)$ precludes statistical analysis of the significance of this difference. The frequency of successful parasite development, expressed as the ratio of sporozoite to oocyst prevalences, was similar for both species. Few field studies on oocyst infections in natural populations have been published. Pringle (1966) and Beier et al. (1987) used the dissection method to test vectors from Tanzania and Kenya, respectively. They obtained lower values than reported here, possibly due differences in the method used. The ELISA method can detect late oocysts only once CSP synthesis has begun (Beier et al., 1988; Sokhna et al., 1998), whereas younger oocysts can be detected by dissection. However, as late oocysts are present for only a short, determinate period of time, whereas sporozoites may persist throughout the life of the mosquito, we would expect to obtain a high sporozoite to oocyst ratio, consistent with our results. This study did not aim to compare the parasite development frequencies obtained by dissection and microscopy with those obtained by ELISA. However, the use of the same method for both vector species and in different field conditions made it possible to compare our ratios as relative parasite development yields.

This study revealed no clear barrier to parasite development once the late oocyst stage had been reached. Parasite development may be limited before CSP synthesis in developing oocysts - from gametogenesis to early oocyst development. These early stages must be studied by other methods, requiring the dissection of fresh mosquitoes and microscopy (Beier et al., 1992). Such methods are not currently suitable for the testing of large numbers of field-collected specimens.

We assumed that the detection of CSP in the head/ thorax and abdomen reflected effective infections of the salivary glands by sporozoites and of the midgut by oocysts, respectively. It has been suggested that the detection of free soluble CSP or sporozoites within the 
hemocoel overestimates the frequency of salivary gland infection (Robert et al., 1988; Beier et al., 1990). If this was the case here, then most insects in which CSP was detected in the salivary glands by ELISA would be expected to have CSP throughout the entire body. However, we found that only $20.0 \%$ of the tested insects were positive for both portions, with $37.5 \%$ having CSP in the head/thorax only and $42.5 \%$ having CSP in the abdomen only (Table I). This suggests that CSP dissemination was not widespread in our study, and that the results accurately reflect the anatomical distribution of $P$. falciparum CSP in the midgut and salivary glands.

The variations of the oocyst and sporozoite indices over time are theoretically linked to both the environment and to the intrinsic susceptibility of the vectors. We found a link with season in An. gambiae s.l., but not for An. funestus. This difference between the two species may reflect differences in their behavior. The highly endophilic resting habits of An. funestus may buffer it from any climatic variation. Indeed, An. funestus mosquitoes generally spend the day in suitable indoor microhabitats, protecting themselves and their parasites against extreme temperatures. An. arabiensis, an exophilic species, is subjected to greater meteorological variations, whereas the endophilic species An. gambiae s.s. tends to behave similarly to An. funestus. The differences in An. gambiae s.l. infection rates according to sampling time may depend on seasonal variations in the proportions of particular species of the gambiae complex. Molecular biology techniques showed that the proportion of An. arabiensis was higher in the dry season, whereas An. gambiae s.s. was more prevalent in the rainy season. This seasonal pattern has previously been described in the Sahel (Touré et al., 1998). An. gambiae s.s. is generally considered to be a more efficient vector than An. arabiensis (Lemasson et al. 1997). We found that the sporozoite to oocyst ratio was lower in the rainy season in An. gambiae s.l., due to a significant increase in oocyst prevalence in the rainy season (chi ${ }^{2}, \mathrm{p}<0.0001$ ). The behavior of An. gambiae s.s. results in more frequent human-vector contact (endophagic, anthropophilic) for this species than for An. arabiensis, possibly accounting for this higher prevalence of oocysts. The parity rate of Anopheles gambiae s.l. did not differ significantly between the two periods. Thus, regardless of the season concerned, the age of the vectors limited the completion of parasite development equally in both mosquito species. The observed variation of sporozoite prevalence according to sampling time, linked to An. gambiae s.s./An. arabiensis ratio, confirmed the greater efficiency of An. gambiae s.s. as a vector. However, the higher sporozoite to oocyst ratio obtained during periods in which $A n$. arabiensis was abundant suggest that the parasite may develop efficiently in this vector after infection.
Our observations highlight the importance of testing for CSP antigen in both the abdomen and head/thorax. Further studies are required to link data obtained with the various methods used in field studies, including dissection and ELISA-CSP in particular, and to identify a marker for the absolute yield of fully developed parasites. However, in addition to classical entomological investigations (species determination, feeding and resting behavior, parity), the method used here is a potentially interesting tool for studies of the effect of environmental conditions on a possible survival bottleneck between the oocyst and salivary sporozoite stages. The environmental modeling of malaria could be used to improve the management of malaria control operations. The approach described here provides a reliable and simple means of exploring complex links in the transmission of malaria in the field.

\section{ACKNOWLEDGEMENTS}

This study received financial support from AMMAEU (African Monsoon Multidisciplinary Analysis), RBM-Sahel and PAL+ initiative from the French Ministry of Research. C.C. holds a fellowship from Fondation Jeunesse Internationale. The monoclonal antibodies were kindly provided by Robert Wirtz, CDC. We thank Richard E.L. Paul and the two anonymous referees for their helpful comments and advice. We also thank the inhabitants of Zindarou.

\section{REFERENCES}

Baudon D., Carnevale P. \& Robert V. Enquête paludologique sur le site du futur barrage de Kandadji. Doc. Techn. OCCGE, $1983, \mathrm{n}^{\circ} 8,177$.

Beier J.C., Perkins P.V., Wirtz R.A., Whitmire R.E., Mugambi M. \& Hockmeyer W.T. Field evaluation of an enzyme-linked immunosorbent assay (ELISA) for Plasmodium falciparum sporozoite detection in anopheline mosquitoes from Kenya. American Journal of Tropical Medicine and Hygiene, 1987, 36 (3), 459-468.

Beier J.C., Asiago C.M., Onyango F.K. \& Koros J.K. ElisA absorbance cut-off method affects malaria sporozoite determination in wild Afrotropical Anopheles. Medical and Veterinary Entomology, 1988, 2, 259-264.

Beier J.C., Perkins P.V., Koros J.K., Onyango F.K., Gargan T.P., Wirtz R.A., Koech D.K. \& Roberts C.R. Malaria sporozoite detection by dissection and ELISA to assess infectivity of Afrotropical Anopheles (Diptera: Culicidae). Journal of Medical Entomology, 1990, 27 (3), 377-384.

Beier J.C., Copeland R.S., Mtalib R. \& Vaughan J.A. Ookinete rates in afrotropical anopheline mosquitoes as a measure of human malaria infectiousness. American Journal of Tropical Medicine and Hygiene, 1992, 47 (1), 41-46. 
Boudin C., Robert V., Carnevale P., Verhave J.P. \& Meuwissen J.H.E.T. Utilisation de la technique ELISA dans le dépistage des moustiques infectés par Plasmodium falciparum. Bulletin de I'Organisation mondiale de la Santé, 1988, 66 (1), 87-97.

Boudin C. \& RoberT V. Plasmodium falciparum : Épidémiométrie de la transmission homme-moustique et de l'infection chez le vecteur. Bulletin de la Société de Pathologie Exotique, 2003, 96 (4), 335-340.

Burkot T.R., Williams J.L. \& Schneider I. Identification of Plasmodium falciparum-infected mosquitoes by a double antibody enzyme-linked immunosorbent assay. American Journal of Tropical Medicine and Hygiene, 1984, 33 (5), 783-788.

Detinova T.S. Age-grouping methods in Diptera of medical importance with special reference to some vectors of malaria. Monogr. Ser. World Health Organisation, 1962, 47 , 13-191.

Julvez J., Mouchet J., Suzzoni J., Larrouy G., Fouta A. \& FonTENILLE D. Les anophèles du Niger. Bulletin de la Société de Pathologie Exotique, 1998, 91 (4), 321-326.

Lemasson J.J., Fontenille D., Lochouarn L., Dia I., Simard F., Ba K., Diop A., Diatta M. \& Molez J.F. Comparison of behavior and vector efficiency of Anopheles gambiae and An. arabiensis (Diptera: Culicidae) in Barkedji, a Sahelian area of Senegal. Journal of Medical Entomology, 1997, 396403.

Robert V., Verhave J.P., Ponnudurai T., Louwé L., Scholtens P. \& Carnevale P. Study of the distribution of circumsporozoite antigen in Anopheles gambiae infected with Plasmodium falciparum, using the enzyme-linked immunosorbent assay. Transactions of the Royal Society of Tropical Medicine and Hygiene, 1988, 82, 389-391.

ScotT J.A., Broodon W.G. \& Collins F.H. Identification of single specimens of the Anopheles gambiae complex by the polymerase chain reaction. American Journal of Tropical Medicine and Hygiene, 1993, 49 (4), 520-529.

Sokhna C.S., Diagne N., Lochouarn L., Rogier C., Trape J.F., Spiegel A. \& Fontenille D. Évaluation comparée par ELISA et par dissection de l'infection plasmodiale des anophèles. Conséquences sur l'estimation de la transmission du paludisme en 1995 à Ndiop, Sénégal. Parasite, 1998, 5, 273279 .

Touré Y.T., Petrarca V., Traoré S.F., Coulibaly A., Maiga H.M., Sankaré O., Sow M., Di Deco M.A. \& Coluzzi M. The distribution and inversion polymorphism of chromosomally recognized taxa of the Anopheles gambiae complex in Mali, West Africa. Parassitologia, 1998, 40 (4), 477-511.

Wirtz R.A., Zavala F., Charoenvit Y., Campbell G.H., Burkot T.R., Schneider I., Esser K.M., Beaudoin R.L. \& Andre R.G. Comparative testing of monoclonal antibodies against Plasmodium falciparum sporozoites for ELISA development. Bulletin of the World Health Organization, 1987, 65 (1), 39-45.

Reçu le 15 février 2006 Accepté le 15 mai 2006 